\title{
Erythrocyte Lipid Abnormalities in Reye's Syndrome
}

\author{
KATHLEEN B. SCHWARZ, SAROJ LARROYA, LAURA KOHLMAN, AND \\ AUBREY MORRISON \\ Department of Pediatrics, Saint Louis University School of Medicine [K.B.S., S.L.] and Department of Internal \\ Medicine, Washington University School of Medicine [L.K., A.M.], St. Louis, Missouri
}

\begin{abstract}
Previous studies have demonstrated alterations in plasma free fatty acid content in Reye's syndrome (RS). We have therefore studied erythrocyte membrane lipids to determine if there are concomitant structural and functional modifications attributable to RS. Erythrocyte lipids were measured in children with RS and in critically ill children also requiring intensive care (ICU). In comatose RS patients erythrocyte phospholipid arachidonate was increased 2 -fold relative to control ICU patients: $20.46 \pm$ 2.14 versus $10.41 \pm 2.32 \%$ of total erythrocyte phospholipid, $p<0.05$. RS coma patients also demonstrated an increased ratio of erythrocyte phospholipid polyunsaturated/saturated fatty acids $(0.76 \pm 0.10)$ compared to ICU controls $(0.48 \pm 0.08, p<0.05)$. Erythrocyte cholesterol was higher in $\mathrm{RS}$ patients $(79.00 \pm 6.61 \mu \mathrm{g} / \mathrm{mg}$ protein) than in ICU controls $(59.74 \pm 6.09, p<0.05)$. Erythrocyte malondialdehyde generation was decreased in comatose RS patients (404 $\pm 28 \mathrm{nmol}$ malondialdehyde/g hemoglobin) versus ICU $(517 \pm 29, p<0.05)$. Although plasma vitamin $\mathrm{E}$ was depressed in RS patients, the erythrocyte vitamin $\mathrm{E}$ concentrations were no different in RS patients than in ICU patients. All RS patients had a typical viral prodrome and either a history of aspirin intake and/or measurable serum salicylate on admission. All of the biochemical abnormalities in RS patients listed above returned to values comparable to those of healthy RS siblings on recovery. The transient nature of these phenomena suggests that they were related to viral infection and/or aspirin rather than to intrinsic differences in lipid metabolism between RS patients and controls. (Pediatr Res 21: 352-356, 1987)
\end{abstract}

\section{Abbreviations}

RS, Reye's syndrome

PUFA, polyunsaturated fatty acids

RBC, erythrocyte

RBC $^{-P L}$, erythrocyte phospholipid

MDA, malondialdehyde

ICU, intensive care unit

SFA, saturated fatty acids

EC, erythrocyte cholesterol

PC, phosphatidyl choline

PE, phosphatidyl ethanolamine

PS, phosphatidyl serine

PL, phospholipid
$\mathrm{RS}$ is an encephalopathy occurring in children subsequent to a viral prodrome. Although the precise cause remains unknown despite two decades of study, there is evidence of a generalized disturbance of lipid metabolism. Pathologically there is "fatty degeneration of the viscera" with small lipid droplet accumulation in liver, brain capillary endothelial cells, kidney (loops of Henle), myocardium, and pancreatic acini (1). In RS patients studied at autopsy, hepatic triglycerides are markedly elevated whereas cholesterol and phospholipids are decreased; in brain, cholesterol is decreased (2).

In plasma of children with RS, free fatty acids are increased whereas triglycerides are decreased (3). Although earlier reports indicated that disproportionate elevation of the plasma concentration of short and medium-chain free fatty acids was characteristic of the free fatty acidemia in RS (4), recently Ogburn et al. (5) have demonstrated that the long-chain PUFA content of the free fatty acid fraction in RS serum is increased whereas the serum phospholipid PUFA are decreased. In vitro and in vivo experiments in animals have demonstrated that polyunsaturated fatty acids can cause cerebral edema (6-8), a cardinal clinical feature of RS. In a rabbit model of RS, Kang et al. (9) have shown that intracisternal injection of free PUFA leads to a reproducible dose-titratable encephalopathy; they and others have proposed that PUFA may be acting as toxins in RS.

There have been no attempts to measure the lipid profile of any tissue during acute RS. Since the majority of PUFA in the cells is in phospholipids, we believe tissue lipid analysis could add to the understanding of the role of PUFA in this syndrome. Hence, we chose to analyze RBC lipids, concentrating on the fatty acid composition of the phospholipids in RS patients in comparison to appropriate controls. Erythrocyte malondialdehyde generation after exposure of erythrocytes to $\mathrm{H}_{2} \mathrm{O}_{2}$, an oxidant stress (10), was also measured as an aid in determining whether or not erythrocyte lipid peroxidation was occurring during RS. Vitamin E, the major lipid soluble antioxidant (11), was also measured in erythrocytes and plasma. In addition to the vitamin's role in protecting PUFA against peroxidation it may also stabilize membrane phospholipids (11) and inhibit phospholipase $\mathrm{A}_{2}$ (12).

Erythrocytes were chosen for the present study because they are readily obtained in a noninvasive fashion and because they are thought to be a reasonable model for the lipids of plasma membranes in general (13). Furthermore, unlike other mammalian cells which can initiate phospholipid synthesis de novo (14), mature erythrocytes can alter phospholipid fatty acids only by deacylation of endogenous phospholipids and reacylation of the resulting lysophospholipids (15) and/or exchange of intact phospholipid molecules with exogenous phospholipids. Since erythrocytes cannot alter fatty acid chain length or the degree of unsaturation (16-20), RBC-PL composition during RS might provide a clue as to host tissue phospholipid composition prior
Received June 23, 1986; accepted November 13, 1986

Supported in part by Grant 5 R23 NS20835-02 from the National Institute of Reyc's Research Fund.

Correspondence and reprints Kathleen B. Schwarz, M.D., Cardinal Glennon Children's Hospital, 1465 S. Grand, St. Louis, MO 63104. 
to the onset of RS or, alternatively, RBC-PL might reflect acute changes in plasma.

Interestingly, RS patients differed from critically ill controls in the composition of erythrocyte phospholipid fatty acids, cholesterol, MDA generation and plasma vitamin E; these data are the subject of this report.

\section{METHODS}

Clinical material. The study was approved by the St. Louis University School of Medicine Institutional Review Board.

$R S$ patients. Fourteen children with a diagnosis of RS were admitted to the study. Diagnosis was made according to criteria established by the Center for Disease Control (21) and staging was done according to the NIH consensus (22). More detailed clinical information is available on request. All RS patients had a typical viral prodrome and either a history of aspirin intake and/or measurable serum salicylate on admission. Patients were managed by careful monitoring and all received intravenous glucose (5-20\% dextrose in a balanced electrolyte solution). In addition the following therapies were employed: intermittent intravenous mannitol $(1 / 4-1 / 2 \mathrm{~g} / \mathrm{kg})(n=13)$, elective intubation and hyperventilation $(n=10)$, pentobarbital coma $(n=4)$, intracranial pressure monitoring $(n=9)$, and controlled hypothermia $(n=2)$. Mean age was $10.2 \pm 1.2 \mathrm{yr}$. None of the patients received a blood transfusion during the study, and none experienced significant blood loss. In the first part of the study, which was conducted in patients $1-7$, plasma vitamin $E$ and neutral lipids were compared to values for healthy controls. The results obtained (see below) served as the motivation for performing the RBC studies described in patients 8-14 and for using critically ill children (ICU) patients as controls for the acute illness. Healthy RS siblings served as controls for the RS patients who were studied after full clinical recovery.

Controls. Healthy Children. These were five healthy children whose blood was obtained after an overnight fast. The mean age was $10.8 \pm 1.0 \mathrm{yr}$.

ICU Patients. The next patient admitted to the pediatric ICU of the same sex and age $\pm 3 \mathrm{yr}$ as the RS patient served as a control for the acute illness. The mean age was $11.7 \pm 0.7 \mathrm{yr}$. Diagnosis in the five ICU controls included liver laceration, open heart surgery, varicella encephalitis, hemolytic uremic syndrome, and Guillain-Barré syndrome.

$R S$ Siblings. These siblings were six healthy children whose blood was obtained after an overnight fast. The mean age was $11.0 \pm 0.8 \mathrm{yr}$.

Sample collection. Blood was collected in EDTA containing tubes and placed on ice immediately. Plasma was separated and stored at $-70^{\circ} \mathrm{C}$ until analysis. Erythrocyte MDA production was studied within $24 \mathrm{~h}$ of sample collection as we determined that the assay was stable at $4^{\circ} \mathrm{C}$ for that length of time. For analysis of vitamin E, phospholipid, and cholesterol, cells were washed three times with 10 volumes of normal saline and then stored at $-70^{\circ} \mathrm{C}$ until analysis.

In the patients, blood samples were drawn on admission, periodically during the acute illness, and on full clinical recovery; a single sample was obtained from each of the controls.

Laboratory studies. Plasma. Vitamin E was measured in all RS patients and control groups according to the method of Martinek (23). Cholesterol and triglycerides (neutral lipids) were measured in RS patients $1-7$ and in healthy children according to Christensen et al. (24). Vitamin E data were expressed as the ratio of vitamin $E$ to neutral lipids. Plasma salicylate was measured on admission (25).

Erythrocytes. These studies were performed in RS patients 814 , in ICU controls, and RS siblings. MDA production by erythrocytes incubated in $\mathrm{H}_{2} \mathrm{O}_{2}$ was measured by the method of Bidder and Jaeger (10). Vitamin E ( $\alpha$-tocopherol) was measured by high-pressure liquid chromatography (26) and expressed on the basis of total lipid (27). Lipids were extracted and analyzed as follows: $0.8 \mathrm{ml}$ of $\mathrm{RBC}$ suspension were hypotonically lysed with $10 \mathrm{ml} 5 \mathrm{mM}$ Tris buffer $\mathrm{pH} 7.4$ and centrifuged at 35,000 $\times g$ at $4^{\circ} \mathrm{C}$ for $30 \mathrm{~min}$. The pellet was resuspended in $10 \mathrm{ml}$ fresh buffer and centrifuged as above. Then the pellet was resuspended in $500 \mu \mathrm{l}$ buffer. An aliquot was taken for protein analysis (28). Four hundred $\mu \mathrm{l}$ of the membrane homogenate were added to $5 \mathrm{ml}$ chloroform:methanol [2:1] (29). The chloroform:methanol extract was then spotted on a thin layer chromatography Silica Gel G plate (Merck, Scientific Products) and developed in the solvent system of petroleum ether:ether:acetic acid $(75: 25: 1)$. Since free fatty acids $(<20 \mathrm{ng} / \mathrm{mg}$ protein $)$, triglycerides ( $<80 \mathrm{ng} / \mathrm{mg}$ protein), and cholesterol esters $(<40 \mathrm{ng} /$ mg protein) were not present in appreciable amounts, these were not analyzed further. For phospholipid fatty acid analysis, silica gel spots were extracted with $500 \mu$ l chloroform to which was added $600 \mu \mathrm{l} 0.5 \mathrm{~N} \mathrm{NaOH}$ in methanol and $2 \mu \mathrm{g} \mathrm{21:0} \mathrm{fatty} \mathrm{acid}$ as internal standard. After $10 \mathrm{~min} 600 \mu \mathrm{l} 6 \mathrm{~N} \mathrm{HCl}$ were added and samples were centrifuged $900 \times g$ for $5 \mathrm{~min}$. The organic phase containing fatty acid methyl esters was dried under nitrogen and resuspended in $10 \mu$ heptane. Subsequently an aliquot $(2-\mu \mathrm{l})$ was injected into a gas liquid chromatography column (10\% SP 2330 on $100 / 120$ Chromasorb WAW). Fatty acid methyl esters were analyzed by flame ionization on a Hewlett Packard 5830A gas chromatograph. The data were expressed as relative area percent (area of individual fatty acid/area of total fatty acids $\times 100$ ). Cholesterol was measured by the method of Lange and Ramos (30).

Statistics. Mann-Whitney two sample test was used. Data are reported as mean $\pm \mathrm{SE}$. $P$ values $<0.05$ were considered to be significant.

\section{RESULTS}

Plasma studies. In patients $1-7$, plasma vitamin E was markedly lower than that of healthy controls (Fig. 1 $a$ ) during the acute illness but returned to control values on recovery without administration of supplemental vitamin $\mathrm{E}$ to the patients. Plasma neutral lipids (triglycerides plus cholesterol) were also depressed in the patients (Fig. 1 $b$ ) in comparison to the healthy children; however, the ratio of plasma vitamin E:neutral lipids was lower in RS patients than controls (Fig. 1c). Values for the RS patients were comparable to those of healthy children on recovery.

These results served as the rationale for the RBC studies described below in RS patients 8-14 and for using critically ill children as controls for the acute illness since it was likely that the nutritional status of the RS patients was more comparable to that of the ICU patients than it was to that of healthy children. Plasma vitamin E was also measured in RS patients 8-14. In Figure 2 plasma vitamin $E$ is shown for this second group of RS patients. Low values very similar to those found in RS patients 1-7 were observed (significantly lower than ICU controls only at $24 \mathrm{~h}$ ). Values for ICU controls in turn were decreased compared to healthy RS siblings (Fig. 2).

Erythrocyte studies. There were several notable differences in RBC phospholipid fatty acids between RS patients (nos. 8-14) and ICU controls during the first $48 \mathrm{~h}$ of hospital admission. In Figure 3, total RBC phospholipid PUFA, consisting of 18:2 + $18: 3+20: 3+20: 4+22: 4+22: 5+22: 6$, and total RBC phospholipid SFA, consisting of 14:0+16:0+18:0, are shown for the various groups. In the RS patients who progressed to NIH stage III-IV coma ("RS coma"), PUFA were increased $(p<$ $0.05)$ while SFA were decreased $(p<0.05)$ as compared to ICU controls; consequently the ratio of PUFA/SFA was about twice as high in comatose RS patients as in ICU controls $(p<0.05)$. Total SFA was also lower in the whole group of RS patients compared to ICU controls $(p<0.01)$. For recovered RS patients versus siblings, values for PUFA were $28.06 \pm 3.40$ versus 26.90 $\pm 4.21 \%$ of total RBC phospholipids; for SFA were $39.81 \pm 2.26$ versus $38.42 \pm 2.32 \%$; and for PUFA/SFA were $0.77 \pm 0.13$ versus $0.76 \pm 0.06$; none of these comparisons was significant. 


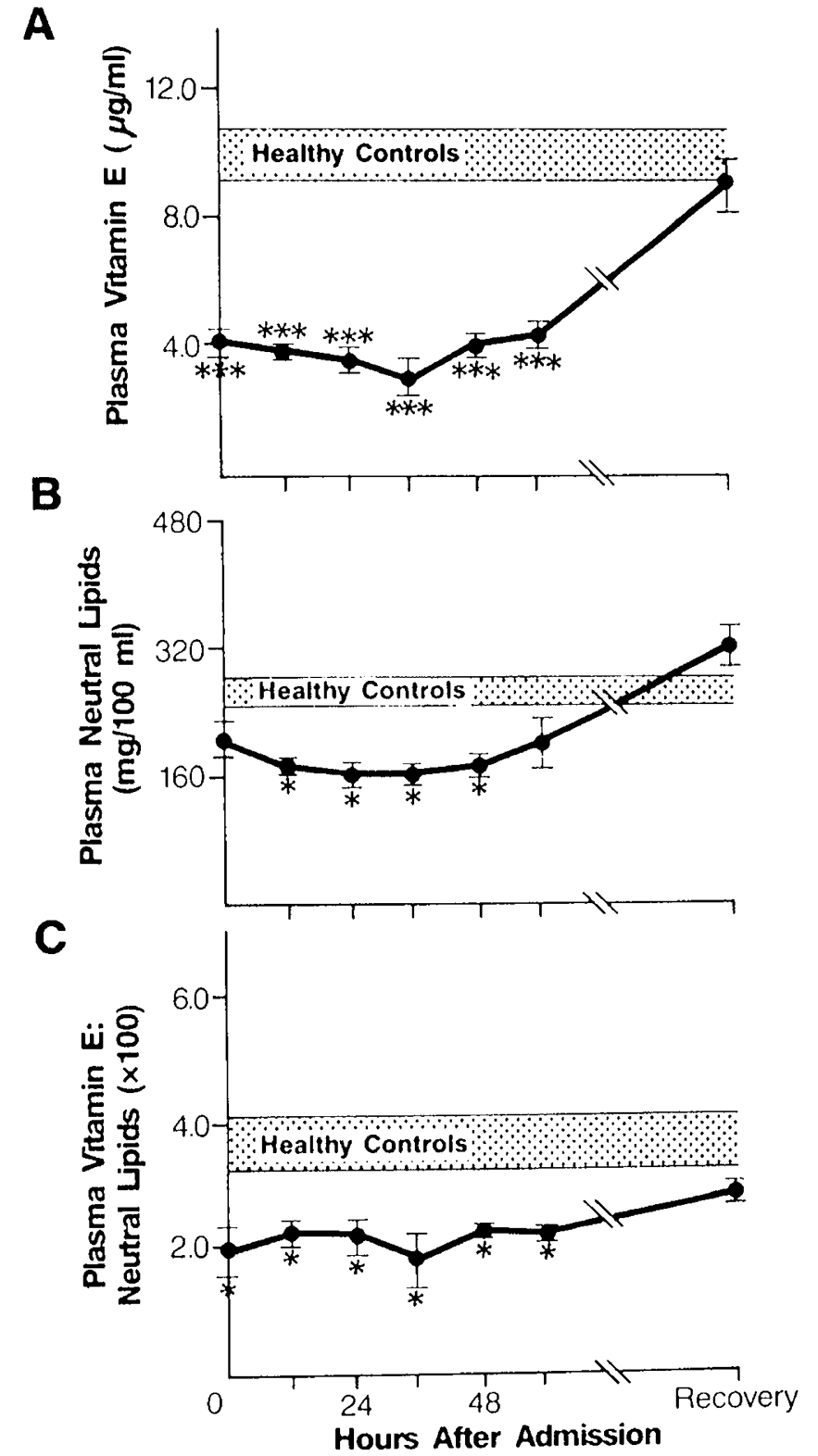

Fig. 1. Time course of plasma vitamin $\mathrm{E}$ and neutral lipids in Reye's patients (nos. 1-7) versus healthy children. Values are represented as mean $\pm \mathrm{SE}$. RS versus healthy controls ${ }^{*} p<0.05,{ }^{* * *} p<0.001$.

Table 1 provides values for individual erythrocyte phospholipid fatty acids. The fatty acids of most interest were 16:0, 18:2, and 20:4. Compared to ICU controls, values for 16:0 were lower for RS patients $(p<0.05)$ whereas those for 18:2 were higher $(p$ $<0.05$ ). The amount of $20: 4$ was also higher in comatose RS patients than ICU $(p<0.05)$, RS sibs $(p<0.05)$, and RS recovery $(p<0.03)$. RS recovery values for all of the major individual erythrocyte phospholipid fatty acids mentioned above (with the exception of 16:0) did not differ from those of RS sibs.

$\mathrm{RBC}$ cholesterol in RS patients was $79.00 \pm 6.61 \mu \mathrm{g} / \mathrm{mg}$ protein, which was higher than that of ICU controls $(59.74 \pm$ $6.09, p<0.05)$ but lower than that of RS sibs $(98.93 \pm 6.73, p$ $<0.05)$. ICU values were lower than sibs $(p<0.004)$. However, $\mathrm{RS}$ recovery values of cholesterol $(65.88 \pm 9.53 \mu \mathrm{g} / \mathrm{mg}$ protein $)$ did not differ significantly from sibs $(p<0.06)$.

Erythrocyte MDA values in comatose RS patients were lower on admission (404 $\pm 28 \mathrm{nmol} \mathrm{MDA} / \mathrm{g}$ hemoglobin, $p<0.05$ ) and days $2-3(371 \pm 54, p<0.05)$ than ICU patients $(517 \pm 29)$. On the other hand, ICU values were higher than RS sibs (430 \pm
$28 \mathrm{nmol} \mathrm{MDA} / \mathrm{g}$ hemoglobin, $p<0.04)$. RS recovery values were similar to those of sibs.

Despite the fact that plasma tocopherol in RS patients during acute illness was lower than values in other groups, RBC tocopherol in the patients $(1.09 \pm 0.42 \mu \mathrm{g} / \mathrm{mg}$ lipid $)$ did not differ significantly from ICU $(0.101 \pm 0.02, p<0.07)$ or sibs $(0.167 \pm$ 0.37 ) because of the wide range of values. Of interest is that three of the RS patients, two of whom were in the coma group, had values as high as $1.69,1.63$, and $2.59 \mu \mathrm{g}$ tocopherol/mg lipid, which were 10-20 times as high as in any of the children from the ICU or sib groups. RS recovery values $(0.51 \pm 0.32 \mu \mathrm{g}$ tocopherol/mg lipid, $p<0.05)$ were higher than those of ICU ( $p$ $<0.05)$.

\section{DISCUSSION}

The decrease in plasma vitamin $\mathrm{E}$ in the RS patients may be secondary to several factors. The least likely is vitamin $\mathrm{E}$ malabsorption since the patients were well-grown children whose plasma vitamin E returned to normal on recovery without dietary vitamin E supplementation. Decreased vitamin E intake may be a partial explanation for the lower values observed in RS patients and probably does account for the decreased plasma vitamin $\mathrm{E}$ in ICU patients (31). The hypolipidemia characteristic of RS patients was probably responsible for the somewhat lower plasma vitamin $E$ values in RS patients compared to ICU controls. An alternative explanation is that the plasma vitamin $\mathrm{E}$ may be low in RS patients because of transfer of the vitamin from the plasma

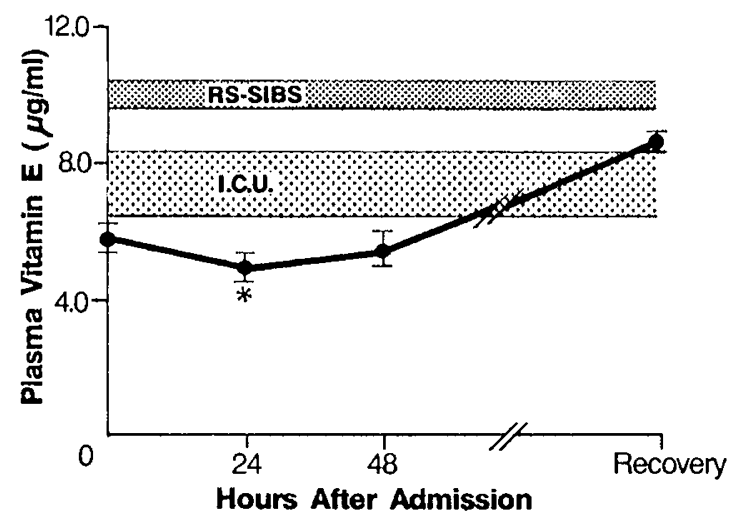

Fig. 2. Time course of plasma vitamin E in RS patients (nos. 8-14) in comparison to ICU and RS sibling controls. Values are represented as mean \pm SE. RS versus $\mathrm{ICU}^{*} p<0.05$. ICU controls were lower than RS sibs $p<0.05$.

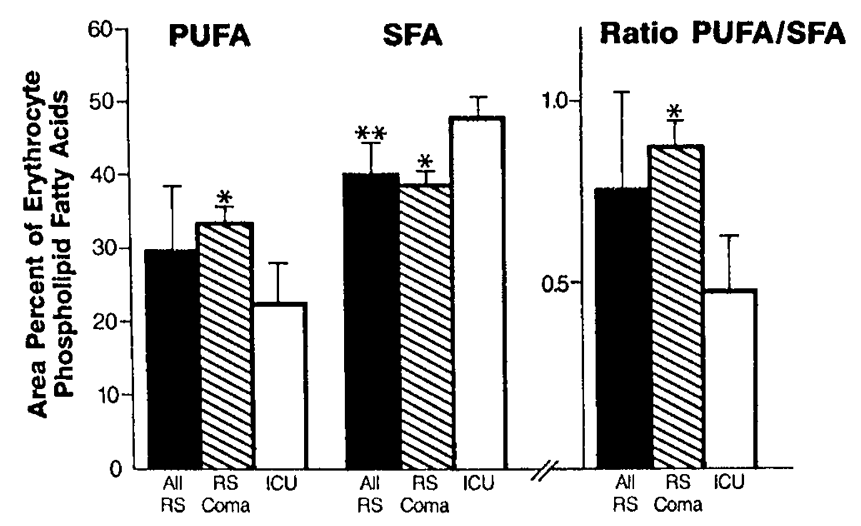

Fig. 3. Relative percent of erythrocyte phospholipid fatty acids in RS patients and ICU controls. RS versus ICU ${ }^{*} p<0.05,{ }^{* *} p<0.01$. Values for RS patients are mean $\pm \mathrm{SE}$ of two to three samples obtained from each patient during first $48 \mathrm{~h}$ of hospital admission. Values in all groups are represented as mean $\pm \mathrm{SE}$. 
Table 1. Major erythrocyte phospholipid fatty acids (relative area percent)

\begin{tabular}{|c|c|c|c|c|c|c|c|c|c|c|c|}
\hline & $14: 0$ & $16: 0$ & $18: 0$ & $18: 1$ & $18: 2$ & $18: 3$ & $20: 3$ & $20: 4$ & $22: 4$ & $22: 5$ & $22: 6$ \\
\hline \multirow[t]{2}{*}{$\operatorname{RS}$ (acute) $(n=7)$} & 0.33 & $20.95^{*}$ & 19.60 & 23.38 & $11.53^{*}$ & 0.05 & 0.92 & 15.76 & 2.04 & 0.10 & 0.26 \\
\hline & \pm 0.12 & \pm 1.23 & \pm 1.36 & \pm 0.79 & \pm 0.82 & \pm 0.03 & \pm 0.36 & \pm 2.40 & \pm 0.72 & \pm 0.09 & \pm 0.18 \\
\hline \multirow[t]{2}{*}{$\mathrm{RS}$ coma $(n=3)$} & 0.20 & $19.13^{*}$ & 19.07 & 23.97 & 12.70 & 0.04 & 0.63 & $20.46^{*}$ & 2.96 & 0.00 & 0.08 \\
\hline & \pm 0.08 & \pm 1.20 & \pm 1.87 & \pm 1.38 & \pm 0.94 & \pm 0.03 & \pm 0.28 & \pm 2.14 & \pm 1.19 & & \pm 0.07 \\
\hline \multirow[t]{2}{*}{$\operatorname{ICU}(n=4)$} & 0.22 & 25.76 & 22.01 & 25.29 & 10.03 & 0.0 & 0.40 & 10.41 & 1.08 & 0.18 & 0.29 \\
\hline & \pm 0.09 & \pm 1.4 & \pm 0.57 & \pm 1.9 & \pm 0.50 & & \pm 0.18 & \pm 2.32 & \pm 0.55 & \pm 0.11 & \pm 0.19 \\
\hline \multirow[t]{2}{*}{ RS sibs $(n=6)$} & 0.35 & 18.99 & 19.13 & 20.09 & 10.05 & 0.10 & 0.89 & 11.54 & 2.27 & 1.08 & 1.56 \\
\hline & \pm 0.10 & \pm 0.95 & \pm 1.48 & \pm 1.35 & \pm 0.66 & \pm 0.05 & \pm 0.27 & \pm 1.96 & \pm 1.13 & \pm 0.51 & \pm 0.65 \\
\hline \multirow[t]{2}{*}{$\operatorname{RS}$ (recovery) $(n=6)$} & 0.21 & $21.93 \dagger$ & 19.39 & 23.59 & 12.05 & 0.05 & 0.73 & 12.47 & 1.69 & 0.19 & 0.56 \\
\hline & \pm 0.19 & \pm 1.91 & \pm 1.77 & \pm 1.99 & \pm 1.42 & \pm 0.09 & \pm 0.35 & \pm 1.44 & \pm 0.53 & \pm 0.18 & \pm 0.31 \\
\hline
\end{tabular}

* RS $v s$ ICU: $p<0.05$.

$\dagger$ RS recovery $v s$ RS sibs: $p<0.05$.

to some lipid rich compartments of the body. Although it was originally thought that there was a positive correlation between plasma and RBC tocopherol (32), Bieri et al. (33) recently demonstrated that induction of hypolipidemia in rats resulted in increased erythrocyte tocopherol independent of dietary vitamin $\mathrm{E}$; some of our RS patients appeared to demonstrate this phenomenon.

The lower RBC MDA values in the comatose RS patients compared to ICU controls are probably explained by the increased amounts of the free-radical scavengers, cholesterol (34), and/or vitamin $\mathrm{E}$ in the RBCs of those patients.

RBCs do not have de novo synthesis of cholesterol from acetate since they lack HMG CoA reductase (35); thus uptake of cholesterol from plasma is the major determinant of EC (36). Factors known to increase EC include liver disease and decreased plasma lecithin:cholesterol acyltransferase (36). Factors that decrease EC include fasting and increased RBC age (36). Prolonged fasting probably accounts for the decreased EC values in both the ICU and acutely ill RS patients.

In order to interpret our findings of altered RBC-PL fatty acids in $\mathrm{RS}$ patients, it is first pertinent to review determinants of RBC-PL fatty acids in healthy man. Exogenous factors known to be of influence include diet, disease, red blood cell age, and the plasma lipid profile. Farquhar and Ahrens (37) showed that in man the linoleic (18:2) and oleic (18:1) contents of RBC-PLs could be influenced by the quantity of these fatty acids in the diet, the changes occurring after ingestion of the diet for about 4-6 wk. Diseases in which RBC fatty acids are abnormal have been reviewed by Nelson (38); however, none has the abnormalities of increased PUFA observed in our RS patients.

The importance of plasma in influencing RBC-PL content was recognized almost two decades ago. The increased serum PUFA in the free fatty acid fraction known to occur in RS (5) may account for some of the increased RBC-PL PUFA which we observed in our patients. RBC-PL classes also influence the RBCPL fatty acid profile since each has a characteristic distribution of fatty acids (39). For example, the increased 18:2 observed in RS RBC-PL could reflect a change in RBC PC (present in the outer sides of the RBC membranes) since 18:2 is more abundant in PC than in other RBC-PL classes (39).

The observed increase in the proportion of RBC-PL PUFA in the comatose RS patients in our study appears to be due primarily to increased RBC-PL 20:4. Of the factors described above which influence RBC-PL fatty acids, those known to decrease RBC 20:4 include liver disease (40), protein-calorie malnutrition (41), biotin deficiency (42), acrodermatitis enteropathica (43), and increased red blood cell age (38). Factors known to increase RBC 20:4 include the newborn state (44) and increased plasma arachidonate. In the study of Ogburn et al. (5), however, serum free arachidonate was not significantly increased in RS patients during the acute illness $(4.5 \pm 3.9 \mu \mathrm{g} / \mathrm{ml})$ compared to recovery $(2.4 \pm 2.0)$. The bulk of RBC-PL arachidonic acid is distributed in PE and PS, both of which are located in the inner RBC membrane (39). In Reed's (18) study of PL exchange between plasma and RBCs there was no metabolic turnover of PS; thus the possibility exists that PE would be the phospholipid most likely to be altered in erythrocytes of patients with RS.

Aspirin has been linked epidemiologically to RS (45), and each of our patients had either a history of aspirin intake, detectable serum salicylate or both. The role of aspirin, if any, in the abnormalities of plasma vitamin $E$ and $R B C$ lipids observed in our RS patients is conjectural. It is possible that the effect of aspirin in inhibiting prostaglandin synthetase (46) in a variety of tissues (the enzyme is not thought to be present in RBCs) results in increased concentrations of 20:4 in plasma during the period of aspirin intake, and secondarily, in the erythrocytes. Aspirin could also increase RBC-PL 20:4 by increasing the acylation of this fatty acid to lysophospholipids (47).

The transient nature of the abnormalities in erythrocyte lipids and plasma vitamin $\mathrm{E}$ observed during acute $\mathrm{RS}$ suggests that children who develop RS do not differ intrinsically in lipid metabolism from their healthy siblings. Studies in humans have shown that neither influenza virus infection alone (48) nor aspirin alone (49) has any effect on serum triglycerides and total cholesterol. Further, influenza virus infection has no effect on serum free fatty acids and phospholipids (48), whereas aspirin may decrease serum free fatty acids $(50)$. The contrast between the abnormalities in plasma as well as $\mathrm{RBC}$ lipid composition in our patients (all of whom had taken aspirin during a viral infection) and the absence of a RS-like pattern in serum lipids with virus infection alone or aspirin intake alone suggests that study of synergistic effects between these two factors on lipid metabolism will be important in RS research. The erythrocyte arachidonate abnormality that we observed in the RS patients, especially when taken in the context of a recent report of lipoxygenase pathway in erythrocytes for metabolism of arachidonic acid (51), merits further investigation in RS patients and animal models of the syndrome.

Acknowledgments. The authors thank C. Fitch, M.D., W. Elliott, Ph.D., P. Kanjananggulpan, P. Patrick, and B. Arey for technical assistance and suggestions; J. P. Keating, M.D. for provision of some of the blood samples; and S. Wunderlich for expert secretarial assistance.

\section{REFERENCES}

1. Devivo DC, Keating JP 1975 Reye's syndrome. In: Schulman I (ed) Advances in Pediatrics. Year Book Medical Publishers, Chicago, pp 175-229

2. Chaves-Carballo E, Ellefson RD 1980 Tissue lipids in hyperammonemic encephalopathies of childhood. Arch Neurol 35:165-167

3. Pollack JD, Hilty MD, Haynes RE, Flynn NM, Cranblett HG 1973 Serum lipid pattern in Reye's syndrome: elevated total free fatty acids. Pediatr Res 7:164FF (abstr)

4. Trauner DA, Nyhan WL, Sweetman L 1975 Short-chain organic acidemia and Reye's syndrome. Neurology 25:296-298 
5. Ogburn PL, Sharp H, Lloyd-Still JD, Johnson SB, Holman RT 1982 Abnormal polyunsaturated fatty acid patterns of serum lipids in Reye's syndrome. Proc Natl Acad Sci USA 79:908-911

6. Chan PH, Fishman RA 1978 Brain edema: induction in cortical slices by polyunsaturated fatty acids. Science 201:358-360

7. Prioleau GR, Fishman RA, Chan PH 1979 Induction of brain edema by fatty acids in vivo. Ann Neurol 6:156

8. Chan PH, Fishman RA 1980 Transient formation of superoxide radicals in polyunsaturated fatty acid-induced brain swelling. J Neurochem 35:10041007

9. Kang ES, Olson G, Jabbour JT, Solomon SS, Heimberg M, Sabesin S, Griffith JF 1984 Development of encephalopathologic features similar to Reye's syndrome in rabbits. Proc Natl Acad Sci USA 81:6169-6173

10. Bidder TG, Jaeger PD 1980 Malondialdehyde production by erythrocytes from alcoholic and non-alcoholic subjects. Life Sci 30:1021-1027

1. Diplock AT 1983 Biology of Vitamin E. Pitman Books, London

12. Douglas $C E$, Chan $A C 1985$ Vitamin $E$ and partially purified phospholipase A. Fed Proc 44:930

13. VanDeenen LLM, DeGier J 1974 Lipids of the red cell membrane. In: Surgenor DM (ed) Red Blood Cell. Academic Press, New York, pp 147-211

14. VandenBosch H, VanGolde LMG, VanDeenen LLM 1972 Dynamics of phosphoglycerides. Ergeb Physiol 66:13-146

15. Mulder E, VanDeenen LLM 1965 Metabolism of red-cell lipids: I. Incorporation in vitro of fatty acids into phospholipids from mature erythrocytes. Biochim Biophys Acta 106:106-117

16. Shohet SB, Nathan DG 1970 Incorporation of phosphatide precursors from serum into erythrocytes. Biochim Biophys Acta 202:202-205

17. Mulder E, VanDeenen LLM 1965 Metabolism of red-cell lipids: III. Pathways for phospholipid renewal. Biochim Biophys Acta 106:348-356

18. Reed CF 1968 Phospholipid exchange between plasma and erythrocytes in man and the dog. J Clin Invest 47:749-760

19. Shohet SB 1970 Release of phospholipid fatty acid from human erythrocytes. J Clin Invest 49:1668-1678

20. Renooij W, VanGolde LMG, Zwaal RFA, Van Deenen LLM 1976 Topological asymmetry of phospholipid metabolism in rat erythrocyte membranes. Eur J Biochem 61:53-58

21. Sullivan-Bolyai JZ, Corey L 1981 Epidemiology of Reye's syndrome. Epidemiol Rev 3:1-26

22. Concensus Conference 1981 Diagnosis and treatment of Reye's syndrome. JAMA 246:2441-2444

23. Martinek RG 1964 Method for the determination of vitamin $E$ (total tocophcrols) in serum. Clin Chem 10:1078-1086

24. Christensen B, Glucck C, Kwiterovich P, deGroot I, Chase G, Heiss G, Mowery R, Tamir I, Rifkind B 1980 Plasma cholesterol and triglyceride distributions in 13,665 children and adolescents: the Prevalence Study of the Lipid Rescarch Clinics Program. Pediatr Res 14:194-202

25. Trinder $P$ 1954 Rapid determination of salicylate in biological fluids. Biochem J 57:301-303

26. Bieri JG, Tolliver TJ, Catignani GL 1979 Simultaneous determination of alpha-tocopherol and retinol in plasma or red cells by high pressure liquid chromatography. Am J Clin Nutr 32:2143-2149

27. Chiang SP, Gessert CF, Lowry OH 1957 Colorimetric determination of extracted lipids. Research Report no. 56-113, Air University School of Aviation Medicine, USAF, TX

28. Lowry OH, Rosebrough NS, Aam AL, Randall RJ 1951 Protein measurement with the folin phenol reagent. J Biol Chem 193:265-275

29. Folch J, Lees M, Stanley GHS 1957 A simple method for the isolation and purification of total lipids from animal tissues. J Biol Chem 226:497-509

30. Lange Y, Ramos BV 1983 Analysis of the distribution of cholesterol in the intact cell. J Biol Chem 258:15130-15134

31. Takeda K, Shimada Y, Amano M, Sakai T, Okada T, Yoshiya I 1984 Plasma lipid-peroxides and alpha-tocopherol in critically ill patients. Crit Care Med 11:957-959

32. Poukka RKH, Bieri JG 1970 Blood alpha tocopherol erythrocyte and plasma relationship in vitro and in vivo. Lipids 5:757-76

33. Bieri JH, Evarts RP, Thorp S 1977 Factors affecting the exchange of tocopherol between red blood cells and plasma. Am J Clin Nutr 30:689-90

34. Demopoulous HB 1973 Control of free radicals in biologic systems. Fed Proc 32:1903-1908

35. Cooper RA 1970 Lipids of human red cell membrane: Normal composition and variability in disease. Semin Hematol 7:296-322

36. Sabine JR 1977 Cholesterol in the Blood. In: Sabine JR (ed) Cholesterol. Marcel Dekker Inc, New York, pp 192-243

37. Farquhar JW, Ahrens EH 1963 Effects of dietary fats on human erythrocyte fatty acid patterns. $J$ Clin Invest 42:675-685

38. Nelson CJ 1972 Lipid composition and metabolism of erythrocytes. In: Nelson CJ (ed) Blood Lipids and Lipoproteins-Quantitation, Composition, and Metabolism. Wiley Interscience, New York, pp 318-386

39. Dodge JT, Phillips GB 1967 Composition of phospholipids and of phospholipid fatty acids and aldehydes in human red cells. J Lipid Res 8:667-675

40. Neerhout RC 1968 Abnormalities of erythrocyte stromal lipids in hepatic disease. J Lab Clin Med 71:438-447

41. Wolff JA, Margolis S, Bujdoso-Wolff K, Matusik K, MacLean WL, Jr 1984 Plasma and red blood cell fatty acid composition in children with proteincalorie malnutrition. Pediatr Res 18:162-167

42. Mock DM, DeLorimer AA, Sweetman L, Baker H 1981 Biotin deficiency: an unusual complication of parenteral alimentation. N Engl J Med 304:820823

43. Cash R, Berger CK 1969 Acrodermatitis enteropathica; defective metabolism of unsaturated fatty acids. J Pediatr 74:717-729

44. Ciccoli L, Hayek Y, Berti D, Bracci R 1981 Fatty acid pattern of the erythrocyte lipids and plasma vitamin $E$ in the first days of life. Biol Neonate 40:187195

45. Hurwitz ES, Barrett MT, Bregman D, Gunn WJ, Schonberger LB, Fairweather WR, Drage JS, LaMontagne JR, Kaslow RA, Burlington B, Quinnan GV, Parker RA, Phillips K, Pinsky P, Dayton D, Dowdle WR 1985 Public health service study on Reye's syndrome and medications, report of the pilot phase. N Engl J Med 313:849-857

46. Ferreira SH, Moncada S, Vane JR 1971 Indomethacin and aspirin abolish prostaglandin release from the spleen. Nature (New Biol) 231:237-239

47. Abdel-Latif AA, Smith JP 1982 Studies on the incorporation of $\left[1-{ }^{14} \mathrm{C}\right]$ arachidonic acid into glycerolipids and its conversion into prostaglandins by rabbit iris. Biochim Biophys Acta 711:478-489

48. Gallin JI, Kaye M, O'Leary WM 1969 Serum lipids in infection. N Engl J Med 1969:281:1081-1086

49. Hamazaki T, Hasunuma K, Kobayashi S, Shishido H, Yano S 1985 The effects of lipids, blood viscosity and platelet aggregation of combined use of niceritrol (Perycit) and a low dose of acetylsalicylic acid. Atherosclerosis 55:107 112

50. Sommariva D, Bonfiglioli D, Zanaboni L, Fasoli A 1981 Effects of acetylsalicylic acid on plasma lipids and on postheparin lipase activities. Int $\mathbf{J}$ Clin Pharmacol Ther Toxicol 19:112-116

51. Kobayaski 'T, Levine L 1983 Arachidonic acid metabolism by erythrocytes. J Biol Chem 10:9116-9121 